\title{
Self-Bag-Drop Simulation Development of Systems for Airport Baggage Handling System
}

\author{
Kang-Seok Lee ${ }^{1}$, Seung-Hun $\mathrm{Kim}^{2}$ and Won-Hyuck Choi ${ }^{3 *}$ \\ ${ }^{1}$ Department of Aeronautic Hanseo University \\ 236-49, Gomseom-ro, Nam-myeon, Taean-gun, 32158 Chungcheongnam-do, \\ Republic of Korea \\ ${ }^{2}$ Department of Aeronautical Systems Engineering Hanseo University \\ 236-49, Gomseom-ro, Nam-myeon, Taean-gun, 32158 Chungcheongnam-do, \\ Republic of Korea \\ ${ }^{3}$ Department of Avionics Engineering Hanseo University \\ 236-49, Gomseom-ro, Nam-myeon, Taean-gun, 32158 Chungcheongnam-do, \\ Republic of Korea \\ ${ }^{1,3}\left\{\right.$ kasulee, choiwh\}@hanseo.ac.kr, ${ }^{2}$ kimsh014@gmail.com
}

\begin{abstract}
The passenger who use airport spend a lot of time in check-in. They are also delayed in their readiness for departure. Therefore, for the decrease in time that is waiting time for handling luggage, recently many airports are expanding self-service. Also, internal development and manufacturing of production automation system and IT technology are world-class. So, for localization of self-bag drop (SBD) system, we think that the application of this system in domestic technique and constructing competitive in customer reception system will be efficient airport management. To this end, for looking for optimal conditions when passengers use SBD, this thesis include development simulation of relevance to a system. Also, this thesis secures information for passenger's in the foreign country airport and simulate this data. Finally, that analysis the best management passenger system when the passenger using SDB.
\end{abstract}

\section{Introduction}

Check-in process for passengers using the airport can take a long time to leave the country and can be significantly delayed until the total number of boarding hours is reached. Consequently, the self-service is being expanded at airports to reduce waiting times when handling baggage.

European airports, including those in other countries, are becoming high-end airports with the introduction of the " net drop " system. Incheon Airport has been test-operated by SBD since February 2015 and local airports in Korea have not yet had an SBD system in place.

Incheon Airport expects terminal saturation as a result of the increase in passenger demand starting in 2015 due to an insufficient number of check-in counters at peak times, but expanding automatic investment limits in its airport facilities to accommodate the growing demand for automated check-in efficiency alone. In case of overseas airports, self-check-in is more active as it is linked to SBD systems, but in case of Korean airports, it is less available than in other developed airports due to the lack of one. Consequently, it is imperative to build SBD systems for the automatic processing of passenger baggage,

Received (January 5, 2018), Review Result (March 18, 2018), Accepted (March 26, 2018)

* Corresponding Author 
along with self-check-in systems to reduce the time to support passenger-signing and operate efficiently [1].

At home, the ability to develop and manufacture production automation systems, and IT technology are world-class. Therefore, it is believed it will graft into local technologies to bring the SBD system home and become a more efficient airport operation with a competitive service. The SBD system is expected to provide convenience for passengers using the airport and to help reduce costs and reduce congestion at the airport construction, which is the main body of airlines and airport operators.

The airport's common system (CUS), one of the major interface systems of the SBD system, has been developed as a next-generation version of the public system (IATA: industrial air handling system). It has been commercialized under a unique brand name called " Air CUS " by Incheon Airport Corporation and Asiana IDT, so it is partially installed, operated and planned to be expanded at Incheon Airport [2].

As such, airport logistics management due to the expansion of the airport logistics processing system using SBD systems is analyzed at appropriate levels and the models of the optimal SBD system are applied to the airport for use in the simulation. The simulation was designed directly for accurate analysis and the design method was used using LabVIEW, which is provided by National Instruments Inc. LabVIEW is the best language for developing scientific and engineering applications, and unlike text-based languages, programs written with icons are written with the term LabVIEW(VI), a virtual machine (VI). LabVIEW is a precise program that allows you to use dataflow programming, where the order in which instructions are executed is determined by the flow of data, unlike other programming languages that determine the sequence in which programs are executed. In addition, real-time actual data from real-time processing and literature were used in combination with direct visits to European and U.S. airports to utilize accurate airport data. The introduction in this paper sets out the necessity and overall direction of the SBD system used and the second part introduces the characteristics of the SBD system's operation. Chapter 3 also discusses SDB systemrelated simulated features and concludes SBD system simulations in Chapter 4.

\section{SBD System}

The SBD systems allow passengers using the airport to consign baggage without carrying it on the plane.

Equipment to reduce wait time by printing the bag and attaching it to the bag on its own from the drop of the self-bag. SBD equipment is a representative technology for turning check-in counters into unmanned during the baggage handling system (BHS: Baggage Handling System). Typical technologies of SBD equipment are currently contributing to the convenience of airport users while reducing the amount of check-in and improving the level of service. The latest plans for use in the Americas, Europe, and Asia.

\subsection{SBD System Operational Features}

Europe's SBD systems provide airlines, airports and ground handling systems for intelligent baggage handling. The main objective is to provide a convenient service for passengers to reduce the time required to check-in baggage. Automated passenger and baggage check-in, SBD and service support are optionally available and are installed in Frankfurt, Munich, Düsseldorf and Nuremberg airports in Germany. No details of the Departure Control System (DCS) or other systems are required, and the bag-flop system, such as scanners, scales, and sensors, is handled by RFID technology.

The SBD system provides baggage check-in and supplementary services, and the baggage check-in processor is supported by the agent. This service is based on CUSS platform integration solutions. The automation system that integrates features to enable 
the customer to check in and process their baggage, dramatically reducing the waiting times for baggage handling, thereby improving customer service and increasing the number of airport users. In addition, the reduction in labor costs through automation results in significant savings in airport operating costs. Figure 1 below shows an SBD system being developed domestically.

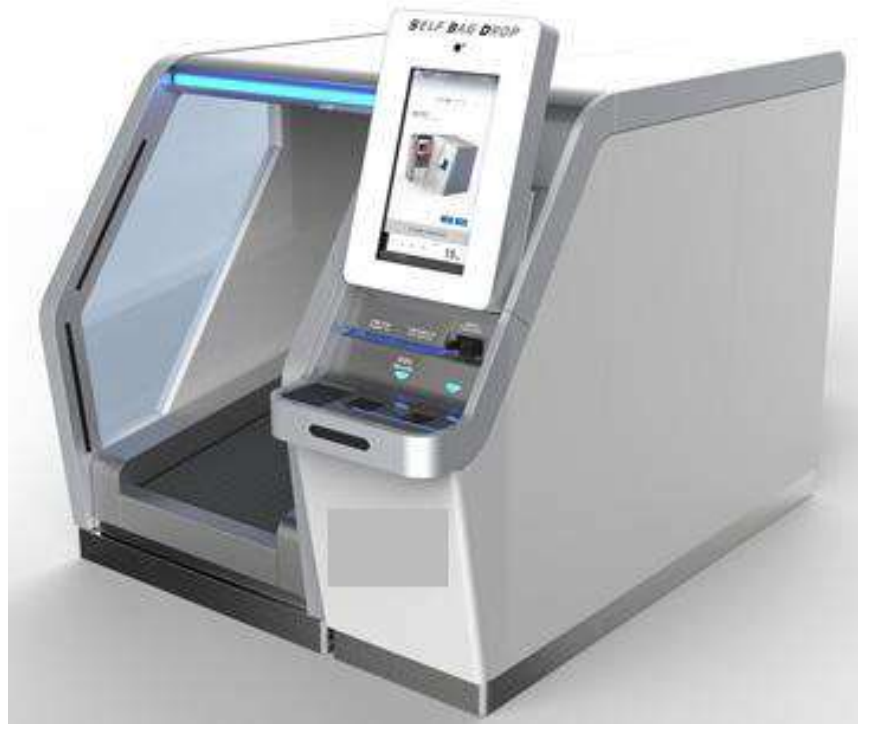

Figure 1. SBD System is being Developed in Korea

\section{SDB System Simulation}

Operation of check-in counters and SBD systems, as applied in the development of simulation models, will be check-in, tagged, quantified and returned to the destination. After baggage has been checked-in from the check-in counter or SBD system, it is sent to the starting luggage sorting area via the counter's conveyor belt. In addition, the small number of check-in counters will cause long queues and wait times and require a large area to accommodate them [7].

Each counter operation shall have a space for handling baggage. Depending on the shape of the counter, the arrangement of the baggage handling space will vary, which will affect the location of the measuring instrument and conveyor belts. Thus, the required space will vary depending on the type of counter. The shape of these counters depends on the terminal design and passenger flow. The counter-unit arm is a starting passenger, depending on the average processing time per passenger. The passenger's convenience and psychological factors shall also be represented. For the calculation of the number of check-in counters, in the Airport digital reference manual (1989), IATA presented the following formula [1].

The number of operating counters shall can accommodate the maximum queue. However, since the costs must be considered, Hon (1999) has proposed an intelligent resource-simulation system as a way to provide maximum service at minimum cost. The system determines the number of check-in counters to meet the demand. Factors needed for calculation include destination, airline, processing personnel and where the service requirements are different. The Intelligent counter simulation system suggests gradually operating more counters during check-in, instead of operating all counters. The service hours of counter operations affect the operator's arm and the required space. Service hours transcended will require more space to accommodate the large crowd, and more check-in counters will be needed to reduce wait time. The composition of the simulation system consists of three main parts, first of which is an ordered, a single array of simulation 
personnel is completed, by commingling them into an array. If you put this heat into one queue at a time, it uses a queue [8].

The second comprises the system check-in area, which is a counter, a circulating area, and a waiting area for passengers to check in, depending on the size and arrangement of the check-in counter and the number of check-in desks. The third circular area is a noninterrupted non-interrupted check-in process for the check-in counter array and for the interruptable check-in processing. As such, the check-in system will affect the passenger circulation area, which will affect the waiting times if a collision between a check-in passenger and a waiting passenger occurs. The waiting area is the area for passengers to wait in, and the queue is determined by the arrival rate of the passengers, the number of counters, and the average check-in time. It also affects latency [9].

Average latency becomes an important measure of service during check-in procedures. The models presented below are the processing models for SBD and check-in counters. Using the processing model of the SBD and the check-in counter, data are calculated in relation to the arrival time of individual passengers in the check-in area. At the check-in area of the airport, the counter arm is expected to affect the airspace required to connect the counter and passengers [4].

The more staff available, the more check-in counter space will be required and the less queue waiting, but the higher the cost of operating a staff member will increase for the airport authority. The optimum plan for the check-in area at an airport is to balance the wait time with the number of responsible personnel. These programs are designed to find a suitable space for balancing the number of employees with the number of passengers. Creates four manned counters and eight baggage handling counters (systems) for the SBD system four (systems) [10] [11].

Turn the cycle by using the word " while. " Here the first cycle is delayed. This is the ' time to travel '. Movement time means the distance from the gate to the Kiosk when passengers arrive at the airport using the airport of works. As the cycle continues to rotate, the eight queues created by the system enter one at the beginning of the queue. In the eight queues, the number of hours that are entered into the " ticketing hours by age " is reflected. At this point, the roof keeps spinning, so if someone is waiting in the " waiting line, " they continue to search for a blank space. The setup variables comprise the journey time to arrive at the airport and to the Self Kiosk, the time to use the Kiosk, the time to operate the SBD, the number of simulation people, and the initial setup screen for the simulation is shown in Figure 2.

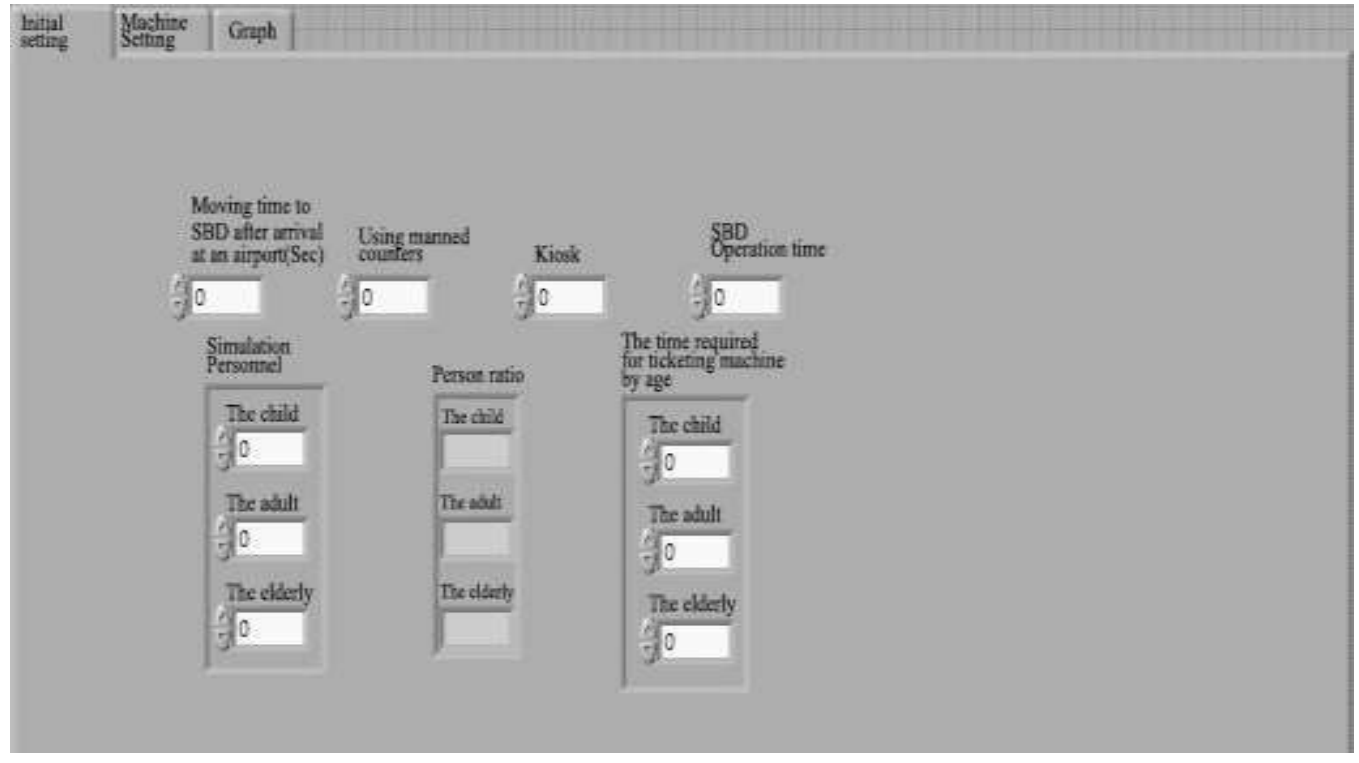

Figure 2. Initial Setup Front Panel 


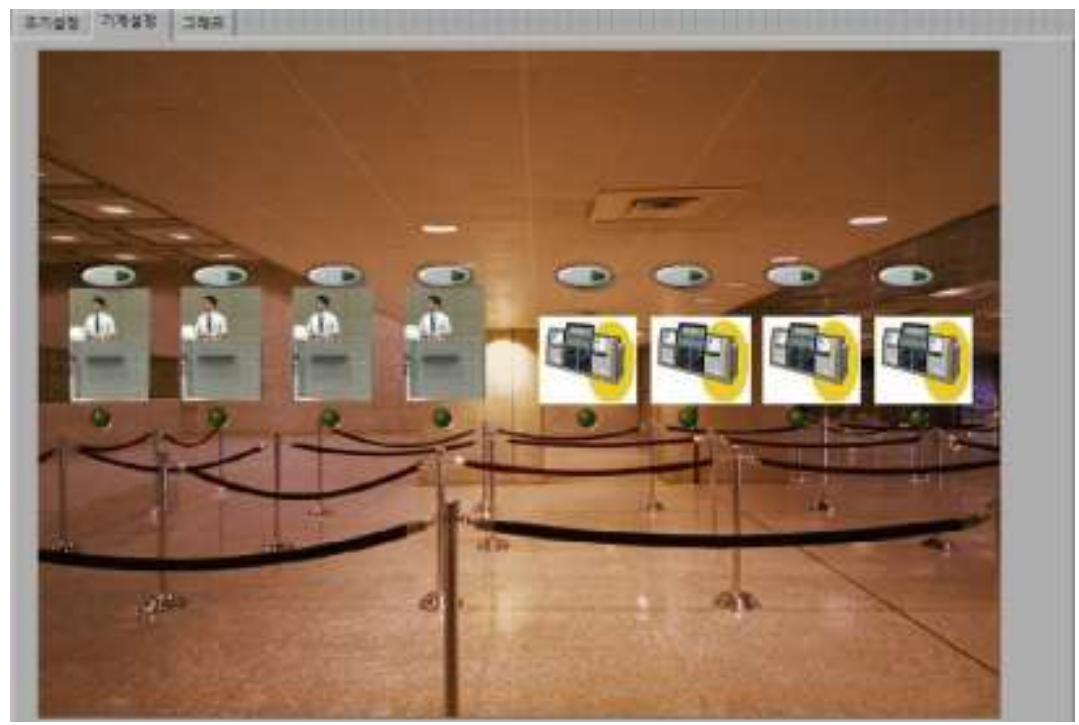

Figure 3. System Settings Portion of the Front Panel

Figure 3 is the front panel portion of the system setup section, which means that the switch and LED actions will be used when the switch is switched on. If the LED on the second tab is on, it means it is being processed and will turn off when a person leaves the machine. And if someone continues to enter the void, they are ordered to go to sea. But the machine that turned off the switch is always on.

The reason is to recognize the machine as being operated to prevent a passenger leaving the line from going to a machine that is not operated.

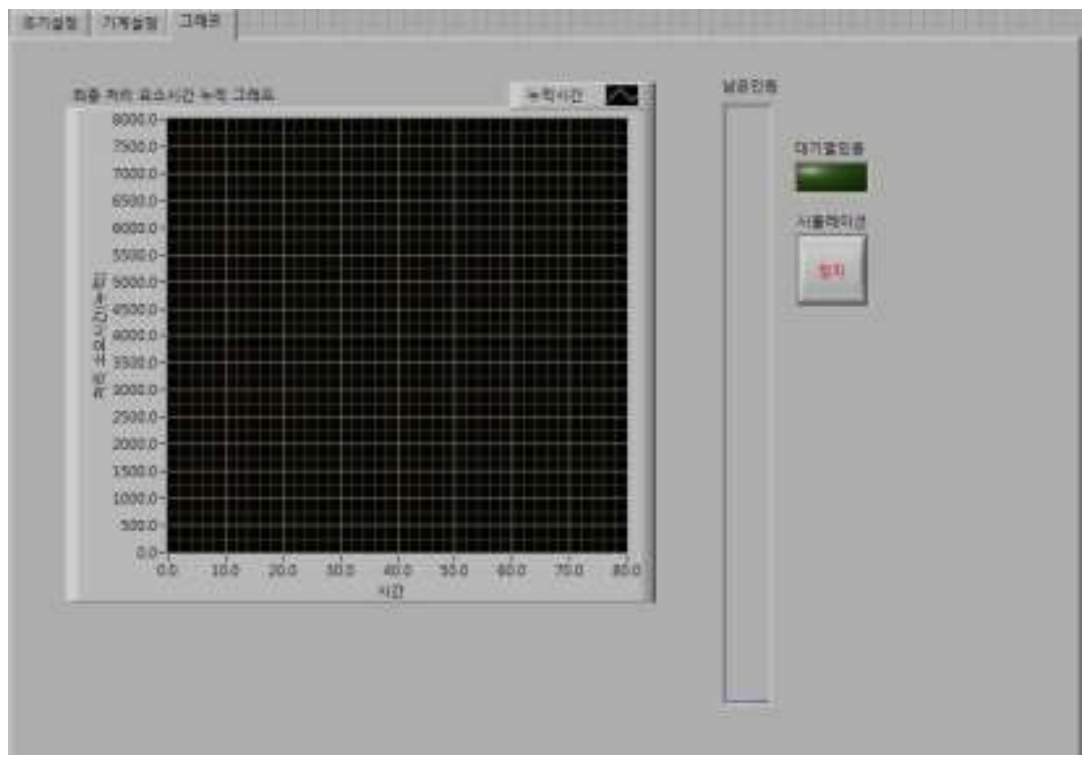

Figure 4. Front Panel Graph

In the graph in Figure 4, the x-axis is associated with the elapsed time and the y-axis is associated with the accumulated time. When the passengers come out of the eight queues, they are displayed on graphs. Passengers entering the four manned counters on the left are accumulated because of a combination of the SBD result in a combination of [Travel Time + Waiting for Line by Age + Hours by Age + Time for a manned counter]. Figure 5 shows a block diagram of SBD system simulations for operating the front panel. 


\section{SBD Operating System}

\subsection{Simulation Model}

SBD systems are divided into two types, one step, and two-step. The first step is to operate baggage compartment in Europe, with all processes, from ticketing to baggage consignment, and the second stage is to print the baggage claim and tag, which is carried out on the cellular phone in the cell. The following table shows the status of airports operating in their respective ways.

However, at some airports, you can also see airports using both SBD systems and traditional manned counters. This simulation compares the accumulated handling time of the SBD system with the accumulated handling time at the airport where the manned counters are installed, and uses the accumulated verification time if the manned counters and SBD systems are used in combination. The maximum number of manned counters installed at existing airports is 4 , and the maximum number of SBD systems is also 4 . For complex counters, the maximum number of combination of manned counters and SBD systems is 8 .

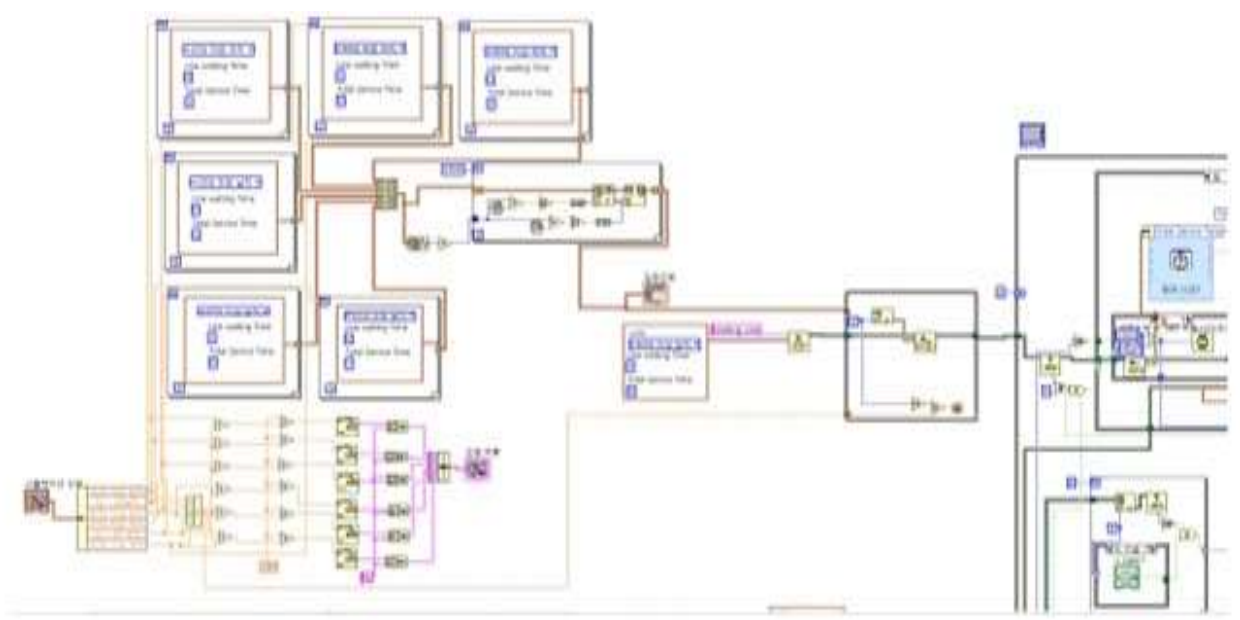

Figure 5. System Simulation Block Diagram

Table 2 shows the parameter values applied to the simulations. The number of passengers is 100 , which represents the distance from the gate to the ticketing location (Kiosk, manned counter, etc.), and the ticketing time is 180 seconds on average. Adults and seniors were divided into all age groups of 50, referring to actual service hours (calculated based on the actual service hours of users under 50 years of age and users over 50 years of age).

Simulate with the same conditions, except for the manned counter and SBD system actuation time. However, for composite systems, the incentive counters, aided by staff, reflected a $50 \%$ reduction in overall ticketing time.

Most passengers use manned counters when using the airport. Ticketing and drop can be done with the help of manned counter employees. As a benefit, the employee's support is needed, which increases the reliability and convenience of the procedure. However, as the number of passengers uses more, the airline's throughput increases, which increases their wait time. Figure 6 shows the accumulated handling time of the luggage when two manned counters are installed, and the right graph shows the accumulated handling time (3150 seconds) of the baggage when four manned counters are installed. The cumulative processing time (approximately 5800 seconds) has been reduced since the two manned counters were installed. 
Table 1. Airport Operations by SBD

\begin{tabular}{|l|l|}
\hline & \multicolumn{1}{|c|}{ Operating Airport } \\
\hline 1-Step & $\begin{array}{l}\text { Orly Airport, Charles de Gaulle Airport, Frankfurt Main Airport, Amsterdam } \\
\text { Airport Schiphol, Brussels Airport, Heathrow Airport...Operating Primarily in the } \\
\text { Europe }\end{array}$ \\
\hline 2-Step & $\begin{array}{l}\text { Los Angeles International Airport, Dallas Fort Worth International Airport, } \\
\text { Chicago O'Hare International Airport, Philadelphia International Airport, Lester } \\
\text { B.Pearson International Airport...Operating Primarily in North America }\end{array}$ \\
\hline
\end{tabular}

Table 2. Simulation Parameters

\begin{tabular}{|c|c|c|c|c|c|}
\hline & $\begin{array}{c}\text { Travel } \\
\text { Time }\end{array}$ & $\begin{array}{c}\text { Manned } \\
\text { Counters }\end{array}$ & Kiosk & $\begin{array}{c}\text { SBD Operating } \\
\text { Time }\end{array}$ & Ticketing \\
\hline $\begin{array}{c}\text { Manned } \\
\text { Counter }\end{array}$ & $120 \mathrm{Sec}$ & $60 \mathrm{Sec}$ & $\mathrm{X}$ & $\mathrm{X}$ & $\mathrm{X}$ \\
\hline $\begin{array}{c}\text { 2-Step } \\
\text { (Kiosk + Bag Drop) }\end{array}$ & $120 \mathrm{Sec}$ & $60 \mathrm{Sec}$ & $30 \mathrm{Sec}$ & $\mathrm{X}$ & $\begin{array}{c}\text { Adult: } 180 \mathrm{Sec} \\
\text { Old: } 300 \mathrm{Sec}\end{array}$ \\
\hline $\begin{array}{c}\text { 1-Step } \\
\text { (SBD) }\end{array}$ & $120 \mathrm{Sec}$ & $\mathrm{X}$ & $30 \mathrm{Sec}$ & $30 \mathrm{Sec}$ & $\begin{array}{c}\text { Adult: } 180 \mathrm{Sec} \\
\text { Old: } 300 \mathrm{Sec}\end{array}$ \\
\hline $\begin{array}{c}\text { Manned } \\
\text { Counter } \\
+ \text { SBD }\end{array}$ & $120 \mathrm{Sec}$ & $60 \mathrm{Sec}$ & $30 \mathrm{Sec}$ & $30 \mathrm{Sec}$ & $\begin{array}{c}\text { Adult: } 90 \mathrm{Sec} \\
\text { Old: } 150 \mathrm{Sec}\end{array}$ \\
\hline
\end{tabular}
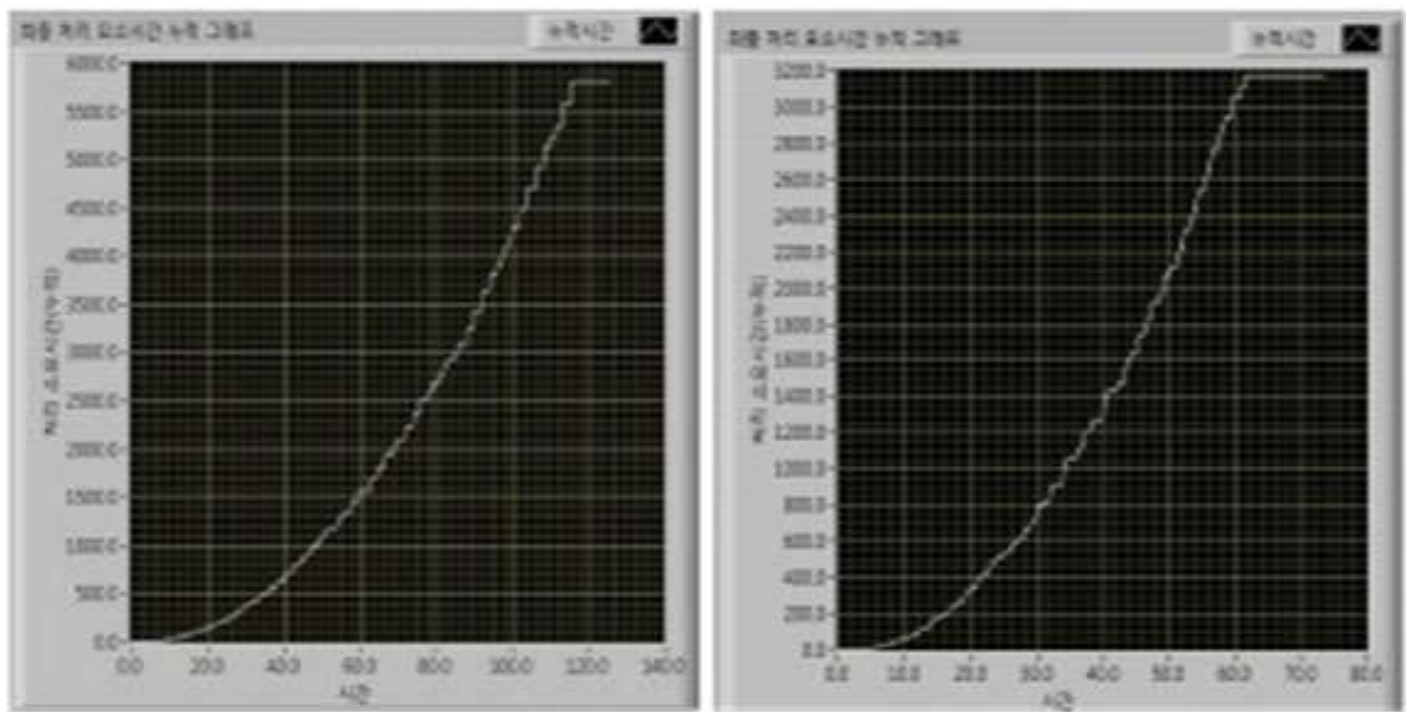

Figure 6. The Graph of the Two Counters Manned Operation (left) during the Four Operating (right)

\subsection{Self-Kiosk + Bag-Drop (2 Step)}

Overall, baggage handling is carried out using the two-step system of the self-kioskbag drop, especially at north-U.S. airports. In case of a bag drop, arrange baggage with the help of an employee after ticketing at the self-kiosk.

Benefits of these systems include the use of a two-step process to distribute passenger traffic at airports, thereby reducing congestion, and reconfirming security at the time of consignment. However, due to overpayment of the bag drop zone, processing time may be delayed. Figure (left) in Figure 7 shows the two manned counters, the running motion and 
the figure (right), comparing the processing time during the two the self-kiosk-bag drop operations. As can be seen in the figure, the cumulative processing time of the two manned counters is increased during the two operations (approx. 6100 seconds), compared to the cumulative processing time (approx. 5800 seconds) of the two inducements. Using a manned counter allows for seamless ticketing with help from employees, whereas the operational capability of a self-kiosk increases the cumulative processing time. The graph in Figure 8 shows the time spent with 100 passengers using four the self-kiosk-bag drop (approx. 3300 seconds). The cumulative processing time can be found to be lower than the two the self-kiosk-bag drop vehicles (approx. 5800 seconds).

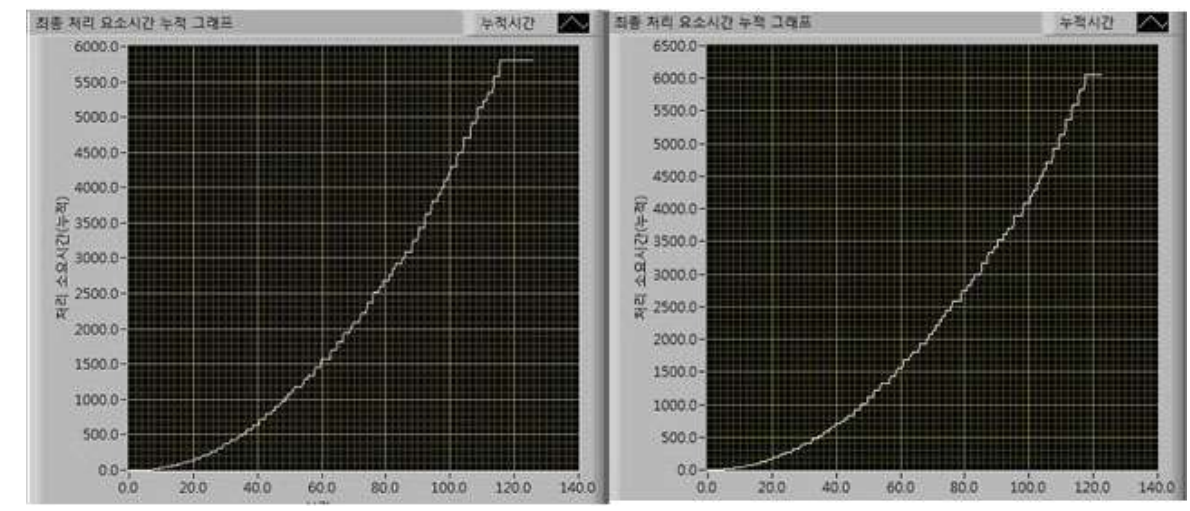

Figure 7. Two Counters Manned Operation (left) during two Self-Kiosk + Bag Drop Operating (right) Graph

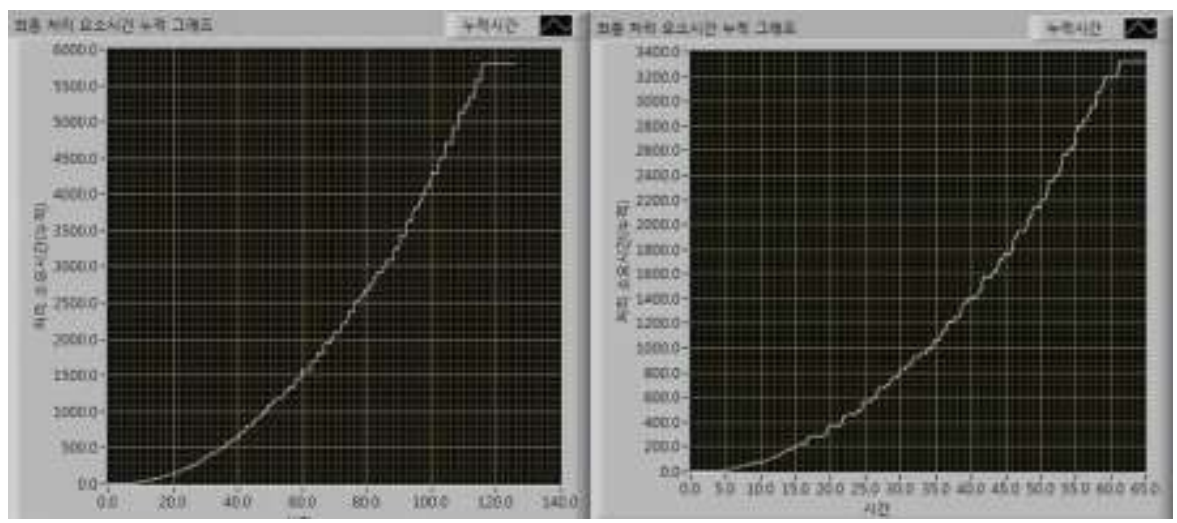

Figure 8. Two Self-kiosk + Bag Drop Operation (left), Four Self-Kiosk + Bag Drop Operation (right)

\subsection{SBD System (1 Step)}

At European hub airports, many passengers use the SBD system to shorten their baggage handling time. The SBD system alone may reduce the congestion at the airport somewhat, but passengers who used the existing manned counters may have a longer handling time as they lack experience with the SBD system.

The graph in Figure 9 shows the time (approx. 6100 seconds) taken to process the use of two SBD systems by 100 passengers. The difference between accumulated processing time (approx. 6000 seconds) when using a single brake + drop and handling time only when using the SBD system is not significant.

The graph in Figure 10 shows the time processed by 100 passengers with four SBD systems. The cumulative processing time can be seen to be lower with the use of two SBD systems. 


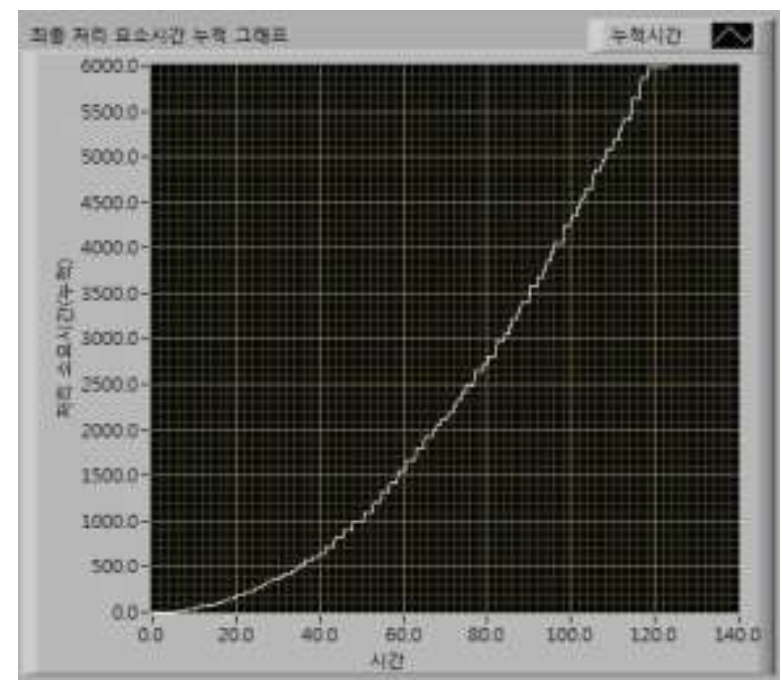

Figure 9. Two SBD System

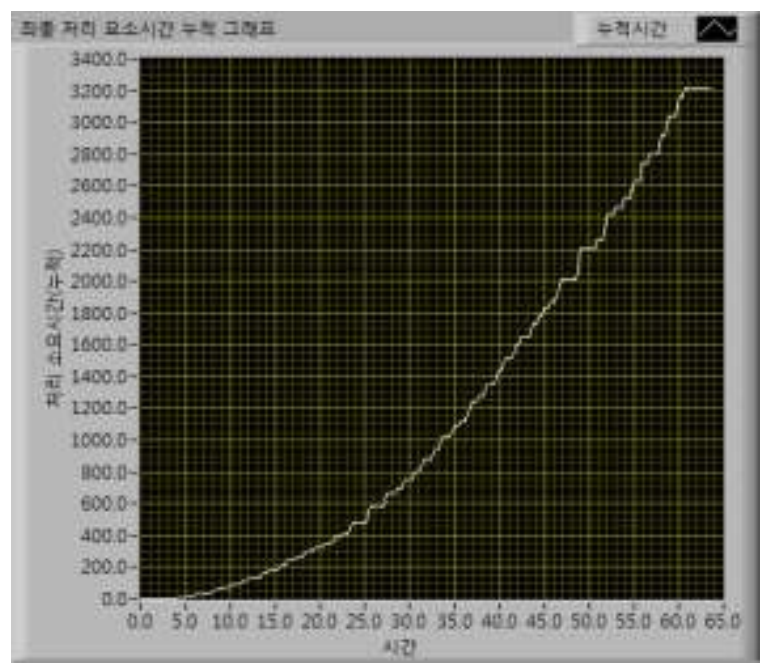

Figure 10. Four SBD System

4.4. Composite Counter (2 Step)

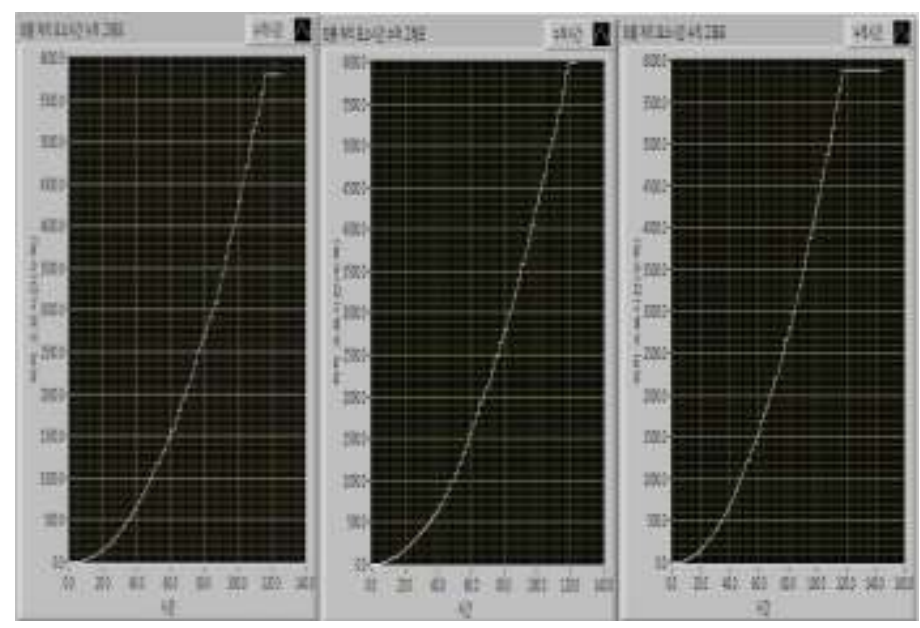

Figure 11. Two Manned Counters (left), Two SBD System(medium), Two Hybrid System (right) 


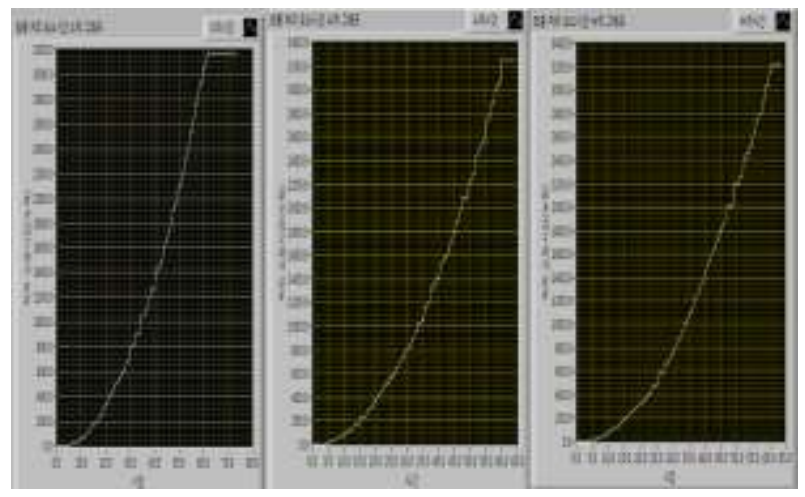

Figure 12. Four Manned Counters (left), Four SBD System (medium), Four Composite System (right)

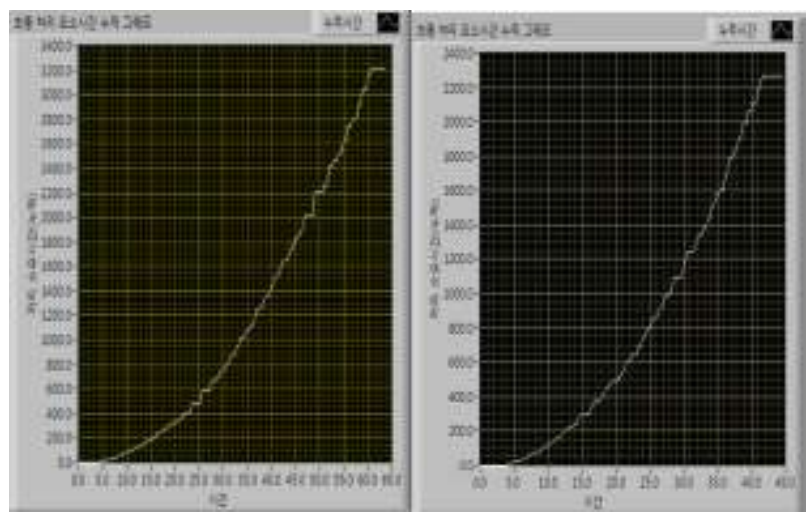

Figure 13. Four Composite Counter (left) and Six Composite Counter (right)

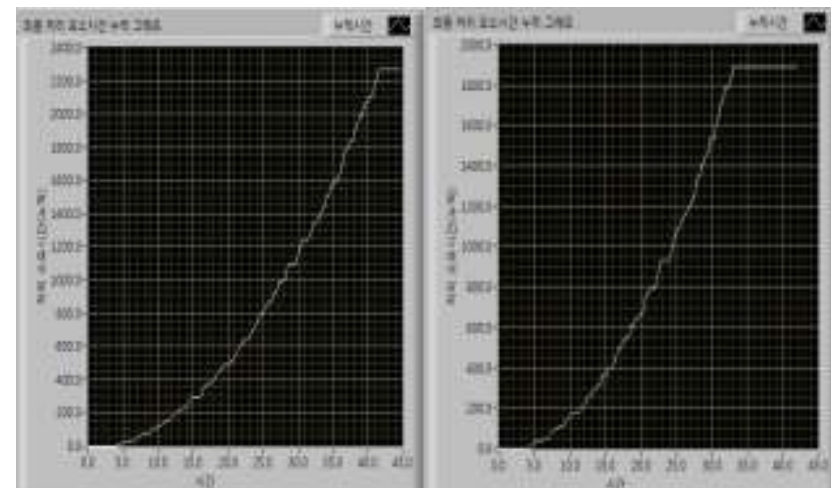

Figure 13. Six Composite Counter (left), Eight Composite Counter (right)

A complex counter is a combination of SBD systems and manned counters. The disadvantage of using only manned counters is that the wait time is extended as passenger's increase. To overcome this disadvantage, the combined use of SBD systems reduces latency and reduces congestion at airports.

The graphs in Figure 11 show the combined operation of one manned counter and one SBD system. The cumulative processing time of the two complex systems (approx. 5900 seconds) has increased over the cumulative processing time (approx. 5800 seconds) of the two manned counters.

The graph in Figure 12 is a graph of two manned counters and a combination of two SBD systems operated. The cumulative processing time (approx. 3,200 seconds) for four complex systems has increased from the accumulated processing time (approx. 3150 
seconds) using the four manned counters to the extent that four SBD systems are capable of being processed.

The graphs in Figure 13 show the combined operation of three manned counters and three SBD systems. Six combined counter accumulated processing times (approx. 2300 seconds) may be seen to have decreased from the accumulated processing time (approx. 3,200 seconds) when four multiple counters are used.

The combined use of a limited incentive counter and an SBD system can reduce the wait time for passengers and reduce congestion at airports by adding more conventional counters.

The graphs in Figure 14 show the combined operation of four manned counters and four SBD systems. Eight combined counter accumulated processing times (approx. 1900 seconds) may be seen to have decreased from the accumulated processing time (approx. 2,300 seconds) when using the six multiple counters.

\section{Conclusion and Review}

\subsection{Conclusion}

Airline Hub mainly use SBD systems to reduce the congestion at airports. In the SBD system, passengers using the airport pass and bag tag are output and luggage is consigned through the bag drop zone in the ' step ' manner. With these SBD systems, although it is possible to reduce the congestion at the airport, the results identified by the simulation model show that the SBD system takes longer to process than the accumulated time at the manned counters. The simulation model shows that the cumulative processing time of the ' 1 Step ', which is used by a single kit and its staff, cannot very much from the accumulated processing time of the SBD system.

At advanced airports, manned counters and SBD systems are used in combination to overcome the limiting problems with manned counters, the congestion at airports as passenger use increases, and the cumulative processing speed of the unmanned counter SBD system. The processing speed of baggage also increases as the passenger's use increases, as is the case with the use of manned counters and baggage handling speed is rapid but limited.

To reduce congestion at these airports, the combination of SBD systems can distribute passengers using the airport and reduce the processing speed. While the cumulative processing time required for the same number of manned counters was higher than the cumulative processing time required for the manned counter, the cumulative processing time taken for complex systems equipped with SBD systems, only SBD systems would have been used.

However, since combined use overcomes the shortcomings of limited incentive counters, cumulative processing time can be found to be less than the single processing time used. In addition, the mix of airport SBD systems and limited incentive counters reduce the wait time and ticket processing time of passengers using the airport, thereby increasing the availability of the airport (i.e., allowing for increased airport satisfaction).

\subsection{Review}

The SBD system reduced the checked baggage (bag attached) placed on the plane by printing itself and integrated bags that allowed passengers to return bags that were not carried with them to the airport, thus reducing the time needed for the bags to be attached. With the ability to reduce latency, airlines can increase passenger ticketing services workload with faster throughput and can use a mix of automated facilities to control the more traditional controlled counters with operational savings. Finally, airports can increase the efficiency of their operations by mitigating congestion in some areas (e.g., 
ticketing counters), provide opportunities to generate non-air revenue and make automated equipment easy to use.

Through improvements, airport reliability could be improved.

However, this simulation did not consider the passenger's position about the convenience of baggage management and the customer's satisfaction with handling, and it should then be reviewed with certain data on passenger satisfaction and convenience.

\section{Acknowledgments}

This study was made by the support of the aviation safety technology development project in 2015, and I would like to thank the concerned ministries.

\section{References}

[1] K. S. Lee, "Airport baggage handling systems, automated airport operations technology development", Ministry of Land, Transport and Maritime Affairs, Sejong-si, Korea, (2012) August.

[2] K. S. Lee and M. S. Jie, "Feasibility study of self-bag drop system applied for airport operations improved", The Korean Society for Aviation and Aeronautics, vol. 23, no. 2, (2015), pp. 75-83.

[3] S. Y. Lee, "Study on the Incheon International Airport baggage handling facility in a durable and reliable operation", Korea Aerospace University, Master's Thesis, (2012) August.

[4] J. S. Kim, "Incheon International Airport HUB Competitiveness Study", Korea Aerospace University, Master's Thesis, (2011) August.

[5] N. J. Ashford, H. P. Martin Stanton, C. A. Moore, P. Coutu and·John R. Beasley, "Airport Operations", 2013 Mc Graw Hill, third edition, (2013), pp. 183-203.

[6] Y. Wells, “Airort Planning \& Management”, Six Edition, (2011).

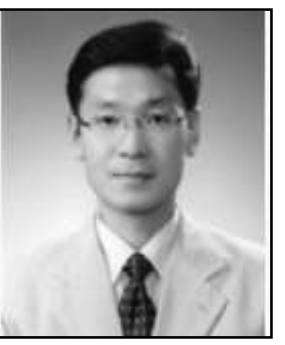

\section{Authors}

Kang-Seok Lee, he received his Ph.D. in Aeronautics and Transportation from KAU in 2000 and is a professor at Hanseo University in 2001. His interests include aviation law, aviation safety and airport operations.

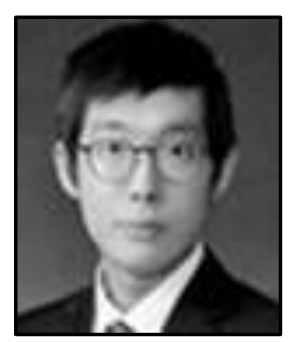

Seung-Hun Kim, he is a master's degree in Aeronautical System Engineering, Hanseo University. He graduated from the Department of Aeronautical and Mechanical Engineering, Hanseo University. He is studying Kalman filters, embedded systems, and smart network communications.

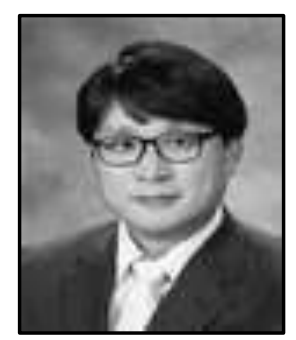

Won-Hyuck Choi (Corresponding author), he received the $\mathrm{Ph} . \mathrm{D}$. degree in avionics from Korea Aerospace University, Korea. He was a Professor of smart network at Doowon Technical University College, Korea. urrently, he is Professor of avionics at Hanseo University, Korea, where he has been since 2014. His present research interests include embedded system, home network. 